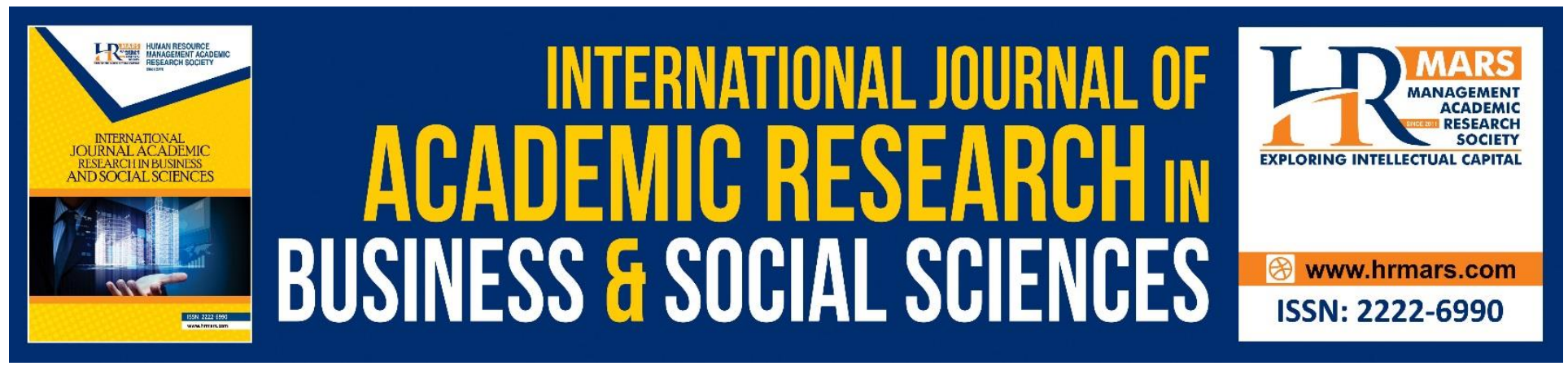

\title{
Drug and Substance Abuse: A Rampant Issue?
}

\section{Badariah Mohd Saad, Siti Ayu Jalil and Azfar Hilmi Baharudin}

To Link this Article: http://dx.doi.org/10.6007/IJARBSS/v8-i11/5575

DOI: $10.6007 /$ IJARBSS/v8-i11/5575

Received: 26 Oct 2018, Revised: 30 Nov 2018, Accepted: 04 Dec 2018

Published Online: 06 Dec 2018

In-Text Citation: (Saad, Jalil, \& Baharudin, 2018)

To Cite this Article: Saad, B. M., Jalil, S. A., \& Baharudin, A. H. (2018). Drug and Substance Abuse: A Rampant Issue? International Journal of Academic Research in Business and Social Sciences, 8(11), 2099-2110.

\section{Copyright: (C) 2018 The Author(s)}

Published by Human Resource Management Academic Research Society (www.hrmars.com)

This article is published under the Creative Commons Attribution (CC BY 4.0) license. Anyone may reproduce, distribute, translate and create derivative works of this article (for both commercial and non-commercial purposes), subject to full attribution to the original publication and authors. The full terms of this license may be seen

at: http://creativecommons.org/licences/by/4.0/legalcode

Vol. 8, No. 11, 2018, Pg. 2099 - 2110

http://hrmars.com/index.php/pages/detail/IJARBSS

JOURNAL HOMEPAGE

Full Terms \& Conditions of access and use can be found at http://hrmars.com/index.php/pages/detail/publication-ethics 


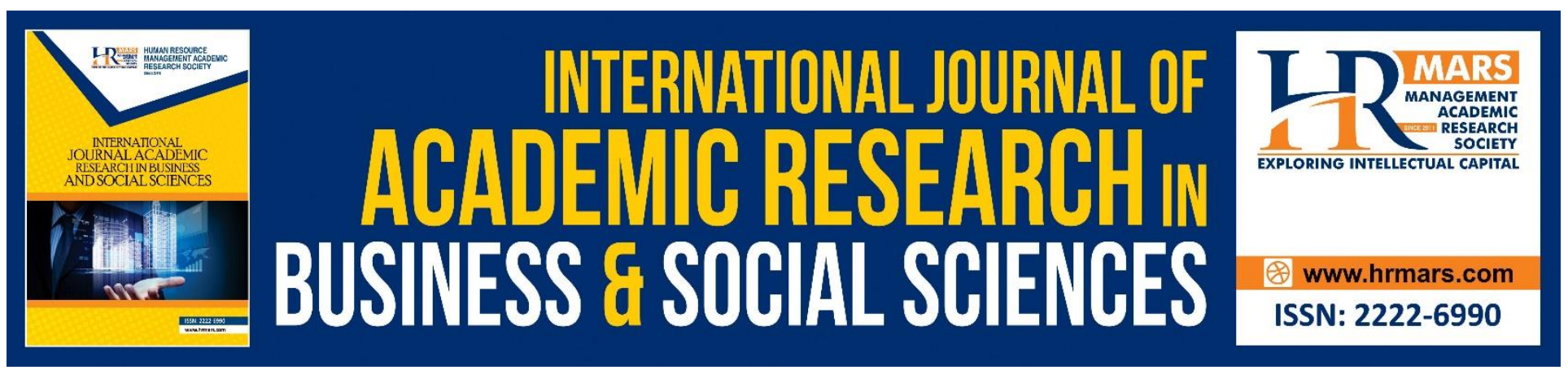

\title{
Drug and Substance Abuse: A Rampant Issue?
}

\author{
Badariah Mohd Saad ${ }^{1}$, Siti Ayu Jalil ${ }^{2}$ and Azfar Hilmi Baharudin ${ }^{3}$ \\ ${ }^{1,2}$ Center of Economics \& Finance, Faculty Business \& Management, Universiti Teknologi MARA \\ Selangor Branch, Puncak Alam Campus, 42300 Bandar PuncakAlam, Selangor, Malaysia. \\ ${ }^{3}$ Faculty Business \& Management, Universiti Teknologi MARA Johor Branch, Segamat Campus, \\ 85000 Segamat, Johor, Malaysia.
}

\begin{abstract}
Background: Transformasi Nasional 2050 (TN50), a new initiative of Malaysia to take the country to greater heights in 2050 would be strenuous if drug abuse among the younger generation in the country is becoming a serious concern. The upward trend recorded involves primary and secondary school children and also students from institutions of higher learning would disrupt the resilience of human capital of a nation. Thus, the increase in the number of drug addicts among youth and social problems relating to drugs which are on the rise is worrisome and needs to be curbed. Objective: This preliminary study is conducted to highlight factors such as knowledge on drugs, environment, lifestyle and law awareness of drugs are of importance that may have impact on drug and substance abuse among college students. Results:270 samples from seven (7) colleges were collected of which about 53 per cent of the respondents are female and the remainder 47 per cent is male. The reliability test of Cronbach alpha scored a highly preferable value of 0.788. Using a binary logistic regression analysis, four of the independent variables i.e. parent's marital status and estimated family's income are found to be significant at 5 per cent significance level. On the other hand, environment and law awareness are significant at 1 per cent and 5 per cent level of significance, respectively. Conclusion: This paper therefore concludes that marital status, family income, environment and law awareness are significant factors in explaining drug and substance abuse among youths.
\end{abstract}

Keywords: Drug Abuse, College Students, Environment, Law Awareness, Knowledge

\section{INTRODUCTION}

Drug addiction is an encumbrance to a nation because the cost of addiction is enormous. The battle against drug addiction has always been an expensive undertaking. It also ditches health care resources. Drug users harm the economy due to the loss of productivity of its human capital. Those with jobs will be less productive as a result of their addiction. Money that could be spent on improving life for a family will be wasted because one of the members is a drug addict. The family of a substance abuser may be living under the poverty line income. Drug abuse would also destruct the communities.

Drug abuse among the younger generation in Malaysia is becoming a serious concern with even 
children as young as seven years old are addicted to it. The National Anti-Drug Agency Malaysia (AADK) prevention director, Abdul Rahman (2015) disclosed that the alarming upward trend recorded every year involves primary and secondary children and also students from institutions of higher learning. It would be a worrying trend, and if proactive measures are not put in place to curb the upward trend, it will become a setback in the route to achieve High Income Nation in 2020.

According to AADK, 15,408 youths were found to be addicted to drugs in 2013 , with the number increasing to 15,897 in 2014, not taking into account anecdotal evidence of unreported cases. The most commonly used drugs by school children and adolescents are opiated, followed by methamphetamine, ganja, and amphetamine-type stimulants (ATS), and psychotropic pills, among others. Additionally, drug abuse cases among youths were mainly recorded in the Klang Valley, Kelantan and Kedah (2015). The main contributing factor to the high incidence of cases in these three areas was the ready availability of drugs, adding that the high-risk locations are in the suburb areas. Apart from peer pressure and exposure, neglect and lack of parental guidance is a factor for the increasing abuse among teens.

In the interest of objectivity, some definition of terms is in order. We define drug abuse as the consumption by oral, intravenous or any other means of non-professionally administered and/or instructed drug intake which has the potential to inflict physical, biological, emotional and psychological harm to the person consuming the drugs. Additionally, a drug addict is defined as any person that habitually engages in drug abuse. These definitions are necessary to distinguish between the administration of drugs by professionals to stem addiction from drug intake by ill-informed individuals. For instance, the administration of methadone would not be categorized as drug abuse unless it is taken without proper oversight.

\section{LITERATURE REVIEW}

\section{Socio-Environmental Pressure and Influence}

As acknowledged by the National Institute of Drug Abuse (NIDA)(2016) in the U.S.A, an important consideration when it comes to delineating the causes of drug abuse cases is the effect of surrounding influencers on a particular subject. Such criteria as family history, prevalence of violence in the community, prevalence of drug abuse amongst peers are some of the top cited gauge of detecting a potential abuser. In particular, youths residing in socio-economically disadvantaged communities whom are exposed to violence, coupled with access to drug is associated with greater drug abuse potential (Walton, et al., 2017). That is, one should not regard the availability of drugs as the sole determinant of abuse. As noted by Banks et al. (2017) for instance, violence is closely related to intoxication. The presence of physical animosity between peers of different cohorts may compel them to resort to stimulant as they engage in the sort of physical confrontation that requires enhancement of energy and focus, of which effect may be found in certain drugs. Marijuana for instance, is often a sought-after substance particularly among young adults as a stimulant to heighten focus and energy.

Delving on the extent of drug abuse, we gather from the literature that peers play an important 
role in affecting frequency of substance intake (Cox, 2014). Thus, the effects of peers are twofold. One is that they act as influencers on young adults to partake in substance abuse activities. Second, is that they act as coaxers in getting their cohorts to increase substance intake. The mechanism of the first peer effect has been discussed in aforementioned literature. The second effect of peer influence arises from the assuring presence of peers. It is a natural social instinct that engaging in certain activities accompanied by peers may give rise to a sense of correctness, albeit falsely so. Hence, mere presence of peers engaging in substance abuse may encourage young adults to increase intake, which in turn gives encouragement to the peer themselves, giving rise to a self-sustaining social support system of abusers. This argument of peer influence is echoed in another paper by Schofield, Conger, and Robins (2015). The authors note that however, a counter balanced force of influence may divert both potential and current intoxicants on a different path. Specifically, parental monitoring and intervention may significantly reduce the intention of using drugs and actual usage of drugs, in the presence of peer influence. This is a significant finding as it suggests that even when abusers are committed to a particular substance intake, parental monitoring and intervention may in fact reverse their behaviour.

\section{Economic Facet}

In continuity of peer influence argument, this paper intends to highlight the effect of socioeconomic background on substance intake. As acknowledged by Sundquist, Sjostedt, Winkleby, Li, Kendler and Sundquist (2016) the neighbourhood in which a person grows up in, is an important determinant. Coined as linking social capital, the authors argue that a poor social network belies an equally poor natural safety net. This lack of linking social capital will result in greater probability of drug abuse, a finding that is consistent in both male and female samples. This paper holds the position that the state of linking social capital is related to the socio-economic state of the community. If effect therefore, a subject whom originates from such a community would also likely be characterized as a low-income individual. In a related study, Alm (2017) finds a correlation between access to resources such as income, and risk of drug abuse. It follows that income of family is a likely determinant of drug abuse. Convoluting matters, as the authors delved into childhood conditions of a cohort of individuals, there is some evidence to point to a conclusion that individuals whom are associated with disadvantaged childhood conditions are also more likely to be associated with higher mortality rate. Moreover, these individuals are recorded to be more severe drug abusers and are less likely to recover from addiction, thus remain as heavy intoxicants.

A survey of injection drug use (IDU) users in Vancouver reveals a more direct link between income and drug abuse. Long et al. (2014) find that the mean income level among IDU users is low. This suggests that poverty is indeed an important risk factor for drug abuse. Economic pressure may indeed induce the need for external stimulant to cope with psychological stress arising from poverty. The problem exacerbates when addiction sets in. Desire for more intoxicants to cope with economic stress coupled with income restrain will force users into criminal activities as means to obtain more stimulants. The result will be a spiral of intoxication and crime. Moreover, left untreated, substance addiction among the poor is likely to result in life expectancy gap between households on the top tier of income spectrum and the bottom tier (Bor, Cohen \& Galea, 2017). 


\section{Concerns of the Law}

The fact that intake of certain drugs is subject to prohibitive sanctions renders provisions of the law itself is of paramount concern. Some may argue that the law should be more punitive to be more effective in reigning in drug abuse. The argument is that that the law should serve as a deterrent and hence be stringent enough to deter potential abusers to consume in the first place. This argument however, fails to recognize that the law takes a back seat for the individuals confronting the environmental and economic pressure discussed earlier. Moreover, increasing the cap for punishment for instance, risks increasing corruption amongst enforcement agencies. Reasoning soundness of the relationship between corruption and severity of the law is backed by numerous studies such as that of (Oleinik, 2016)

Alternatives to increasing legal rigour that is also gaining traction among activists and academics are policy actions that favour promotion of public health over criminalization of drug use. A framework which recognizes human rights and public health ensures the risk of drug abuse among vulnerable communities is minimized. For instance, inhumane treatment of sex workers by law enforcers and the public will drive them in seclusion and alienation. This will in turn, lead to additional psychological stress which will ultimately increase substance abuse among these communities. What is needed on the other hand as argued by the authors, is a systemic approach which takes into account aforementioned considerations. As in the previous case for example, it would be more effective if government agencies engage with said community in an effort to comprehend the psychological and environmental challenges faced by them and implement economic empowerment initiatives to eliminate incentives of drug abuse. Additionally, the authors note that apart from provisions of the law, mechanism of enforcement too plays a critical role in determining users' behaviour and thus, their decision to consume. Treating individuals with drug addiction more as patients than as criminals would encourage many to approach relevant agencies to overcome their addiction. This tactical shift would not only abate drug abuse, but also other drug-related conditions such as HIV (Strathdee, Beletsky \& Kerr, 2015).

\section{Marital Status}

As cited in Vassliki (2013), an updated version of Amato and Keith's study which was recently published includes studies that were done in the 90's showed similar results of the original study; children from divorced families scored lower on assessments of academic achievement, adjustment, and well-being although the observed differences are modest. According to Brody $\mathrm{GH}$, Neubaum E, Forehand R and Hetherington EM, Camara KA as cited in (2013), divorce affects the social, emotional and cognitive adjustment of children leading to disruption of their functioning which lasts for 2 years after the divorce. However, the results of the studies about longer-term divorce outcomes on social, emotional and cognitive development of children are contradictory. Referring to Vassliki (2013), children from divorced families reported more substance use, oppositional or aggressive behaviour and depression than the children from intact families. The results of the study by Vassliki (2013) suggest that there are relationships between parental divorce and adolescents' well-being. Adolescents from divorced households seem to function worse than their peers from married families 
INTERNATIONAL JOURNAL OF ACADEMIC RESEARCH IN BUSINESS AND SOCIAL SCIENCES

Vol. 8, No. 11, Nov, 2018, E-ISSN: 2222-6990 (C) 2018 HRMARS

in many areas. Consequently, interventions should be planned and made in order to protect adolescents, as well as children, from the possible deleterious effects of a divorce.

\section{RESEARCH METHODOLOGY}

A total of 270 respondents from seven (7) public and private universities were chosen based on convenient sampling method. These universities are Universiti Teknologi MARA (UiTM), Universiti Putra Malaysia (UPM), Universiti Kebangsaan Malaysia (UKM), Universiti Selangor (UNISEL), Universiti Tenaga Nasional (UNITEN), Universiti Infrastruktur Kuala Lumpur (IUKL) and Management and Science University (MSU). The survey consists of three parts of which, the first part identifies the respondents' demographic profile. The second part of the questionnaire examines the potential factors leading to drug abuse such as 'knowledge', 'environment', 'lifestyle', and 'law enforcement' on the respondents. A five-point Likert-type scale measurement was utilized, ranging from 'strongly disagree' (1) to 'strongly agree' (5). The third part was an open-ended question asking their opinion about ways to curb drug-abuse among students.

The data was initially subjected to the reliability test before researchers proceed to conduct the factorial analysis and logistic regression to determine the significant factors contributing to drug abuse. The proposed research model listed the factors which leads to drug abuse are environment, law awareness, knowledge on drugs and lifestyle. Accordingly, these independent variables are the hypotheses that would be tested.

As mentioned earlier the preliminary analysis begins with conducting the reliability test based on the statistical value of Cronbach Alpha to assess the internal consistency of the 'goodness' of the questionnaire or survey employed to measure the concepts. At first there were twenty-seven (27) items however four (4) items were removed since the correlation score of these items was very low (less than 0.2). The alpha score for the 5-point Likert scale with twenty-three (23) items is 0.788 indicating a high internal consistency. The score for each five constructs or concepts is shown in Table 1. The values yielding from 0.753 to 0.909 further confirmed the internal consistency of the instrument measuring each concept.

Table 1: Summary of Reliability analysis

\begin{tabular}{lllcl}
\hline Variable & Items & Mean & $\begin{array}{c}\text { Standard } \\
\text { Deviation }\end{array}$ & $\begin{array}{l}\text { Cronbach } \\
\text { Alpha }(\alpha)\end{array}$ \\
\hline Environment & 11 & 26.24 & 10.819 & 0.909 \\
Law & 6 & 23.08 & 4.938 & 0.828 \\
awareness & 2 & 6.23 & 2.493 & 0.788 \\
Lifestyle & 3 & 12.65 & 2.174 & 0.753 \\
Knowledge & & & & \\
\hline
\end{tabular}

\section{FINDINGS AND DISCUSSION}

From 270 sets of questionnaires collected and usable, majority of the respondents, 52.6 percent were female and 47.4 percent is male. Out of this 71 percent comprised of Malay, whereas the Chinese and Indian were only 18 percent and 10 percent respectively. Among these respondents, more than 
half were age between 16 to 24 years old, and less than one-fifth were 25 years above. Majority of them are pursuing their Bachelor degree while only a small number of them are postgraduate students. Approximately 86 percent of their parents are with married status and a small fraction were divorced or separated. On the part of family's earning per month, about 32 per cent is within the range of RM3001 to RM6000 whereas 28 per cent stated less than RM3000 and within the range RM6001 to RM12000. An essential dichotomous type of question that was asked among the respondents is whether they have taken illegally any drugs for the past 6 months. This dichotomous question becomes the dependent variable in the analysis. It seems that only 21 per cent of the respondents answered 'yes' compared with 'no' 79 per cent.

The exploratory factor analysis was conducted on the items of questionnaires in order to place them into meaningful or appropriate categories. The main aim is to get an underlying concept that able to facilitate interpretations. The overall model was statistically acceptable indicated by KeiserMeyer-Olkin (KMO) measure of sampling adequacy for 23 items with a value of 0.889 and significant at 1 per cent significance level as presented in Table 2(a). Moreover, to determine how well the model is able to predict the correct category (taken drugs or not taken drugs illegally) was shown by the classification table in the output. The results indicated that the model correctly classified 90.7 per cent of cases overall, an improvement over the 79.3 per cent in the beginning block. Meanwhile Table 2(b) portrays the results based on a four (4) structure solution which are environment, law awareness, lifestyle and knowledge.

Table 2(a): Summary of Factor Analysis for twenty-three (23) items

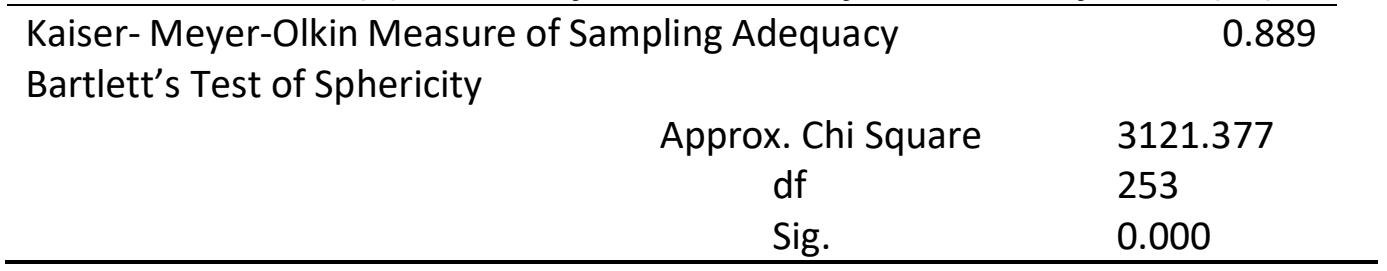

Table 2(b): Summary of Factor Analysis for Construct Validity

\begin{tabular}{llll}
\hline Construct & $\begin{array}{l}\text { KMO Measure } \\
\text { of Sampling } \\
\text { Adequacy }\end{array}$ & $\begin{array}{l}\text { Initial } \\
\text { Eigenvalue }\end{array}$ & $\begin{array}{l}\text { Cumulative percent } \\
\text { of Explained } \\
\text { Variance }\end{array}$ \\
\hline Environment & 0.905 & 5.834 & 53.033 \\
Law awareness & 0.837 & 3.253 & 54.219 \\
Lifestyle & 0.500 & 1.655 & 82.741 \\
Knowledge & 0.678 & 2.020 & 67.327 \\
\hline
\end{tabular}

Table 3 indicates the summary of the exploratory factor analysis (EFA) of items for each construct or factor structure (termed as component). The individual KMO shows environment scored the highest with 0.905 followed by law awareness (0.837), knowledge (0.678) and lifestyle (0.500). Since lifestyle scored the lowest value out of the 4 structure categorized under component number 3 which listed only two items, subsequently, the construct 'lifestyle' failed to fulfil the criteria (minimum KMO 0.6 with three items) and thus deleted from the logistic regression. 
INTERNATIONAL JOURNAL OF ACADEMIC RESEARCH IN BUSINESS AND SOCIAL SCIENCES

Vol. 8, No. 11, Nov, 2018, E-ISSN: 2222-6990 @ 2018 HRMARS

Table 3: Summary of Exploratory Factor Analysis

\begin{tabular}{lcccc}
\hline Variable & \multicolumn{3}{c}{ Component } \\
\cline { 2 - 5 } & 0.732 & & \\
\hline Curiosity & 0.684 & & \\
Friends insist & 0.656 & & \\
Enjoy smoking & 0.640 & & \\
Experiment with friends & 0.762 & & \\
Neighbourhood & 0.611 & & \\
Family members & 0.617 & & \\
College environment & 0.644 & & \\
Easy drugs & 0.641 & & \\
Monthly allowance & 0.728 & & \\
Regular party-goer & 0.621 & & \\
Hang-out in bars \& clubs & & 0.441 & & \\
Drug is illegal & & 0.660 & & \\
Death penalty & 0.786 & & \\
Agree penalty & & & \\
Report authority & 0.821 & & \\
Place to report & & & \\
Support campaign & & & & \\
& & & & \\
\hline Night activities & & & \\
Spend friends & & & \\
Aware danger of drug abuse & & & \\
Aware of effects & & & \\
Government's campaigns & & & \\
\hline
\end{tabular}

The logistic regression analysis presented in Table 4 stated the values of Cox \& Snell R Square and Nagelkerke R Square as 0.401 and 0.628 respectively. These two values of pseudo $\mathrm{R}^{2}$ given by Model Summary indicate how much variation in the dependent variable is explained by the model. Hence, it implies that the variation in drug abuse can be explained by this set of variables is between 40 per cent and 62.8 per cent. On one hand, the Hosmer-Lemeshow test describes the reliability test of the model goodness fit indicated by the chi-square value is 3.177 with a significance level or $p$-value of 0.923. Since this significant value is larger than 0.05 , therefore indicating support for the model. 
INTERNATIONAL JOURNAL OF ACADEMIC RESEARCH IN BUSINESS AND SOCIAL SCIENCES

Vol. 8, No. 11, Nov, 2018, E-ISSN: 2222-6990 @ 2018 HRMARS

The next essential analysis is to investigate the importance of each predictor variables. The variables that are significant having the $p$-values below 0.05 were 'parent's marital status,' 'family income monthly' which range between RM3001-RM6001 and RM6001-RM12000, and 'law awareness' with each 5 per cent significance level, respectively, whereas the factor 'environment' stated a one per cent significance level. Meanwhile 'gender', 'ethnicity' and 'knowledge' were insignificant. For each of the odds ratio shown in Table 4 there is a 95 per cent confidence interval displayed with a lower and an upper value. For example, parent's marital status that has a negative significant coefficient means that those respondents' whose parents' status are divorced were 4.132 times more likely to take drugs than those whose parents' status are married.

For estimated family income per month, it seems to indicate that the higher the family income the less likely they will take drugs. Moreover, if the environment or surrounding of drugs worsening, these students would be 4.651 times more likely to take drugs. However, law awareness is the only predictor or factor with the coefficient showing a positive significant value. This can be interpreted as students who are less aware about the country's stringent law on drugs would less likely to answer no to the question whether they have illegally taken drugs for the last 6 months.

Table 4: Logistic Regression Analysis Examining Drug Abuse

\begin{tabular}{|c|c|c|c|}
\hline Variable & B (S.E.) & Wald $\left(\chi^{2}\right)$ & $\begin{array}{l}\text { Odds Ratio } \\
\text { (95\% C.I. with lower \& } \\
\text { upper values) }\end{array}$ \\
\hline Gender (1) & $0.751(0.477)$ & 2.481 & $2.120(0.832 \& 5.401)$ \\
\hline \multicolumn{4}{|l|}{ Ethnic Group: } \\
\hline Malay & $1.182(1.386)$ & 0.728 & $3.262(0.216 \& 49.366)$ \\
\hline Chinese & $0.030(1.494)$ & 0.000 & $1.030(0.055$ \& 19.265) \\
\hline India & $0.429(1.438)$ & 0.089 & $1.536(0.092 \& 25.718)$ \\
\hline Parents' Marital Status (1) & $-1.420(0.613)$ & $5.373 * *$ & $0.242(0.073 \& 0.803)$ \\
\hline \multicolumn{4}{|l|}{ Family Income Monthly: } \\
\hline Less than RM3000 & $-0.430(0.721)$ & 0.356 & 0.650 (0.158 \& 2.675) \\
\hline RM3001-RM6000 & $-1.560(0.699)$ & $4.980 * *$ & $0.210(0.053 \& 0.827)$ \\
\hline RM6001-RM12000 & $-1.814(0.786)$ & $5.321 * *$ & $0.163(0.035 \& 0.761)$ \\
\hline \multicolumn{4}{|l|}{ Factors: } \\
\hline Environment & $-1.538(0.287)$ & & 0.215 (0.122 \& 0.377) \\
\hline Law Awareness & $0.683(0.302)$ & $28.726 * * *$ & 1.979 (1.094 \& 3.581) \\
\hline Knowledge & $-0.073(0.350)$ & $5.097 * *$ & 0.929 (0.462 \& 1.868) \\
\hline \multirow[t]{2}{*}{ Constant } & $3.590(1.925)$ & 0.042 & 36.226 \\
\hline & & $3.478 *$ & \\
\hline
\end{tabular}

\begin{tabular}{lc}
\hline Cox \& Snell R Square & 0.401 \\
Nagelkerke R Square & 0.628
\end{tabular}

Hosmer and Lemeshow Test Chi-square3.177

Note: $* * * \frac{(p \text { value })}{1 \%, * * 5 \% \text { and } * 10 \% \text { significance level }}$ 


\section{CONCLUSION}

The results of the study show that parent's marital status, family income monthly, law awareness and environment could be the factors to drug abuse among youngsters. Regardless of gender, ethnicity and the level of knowledge on drugs; youngsters are at high risk to drug abuse. The result is consistent with the findings in the study by Mohd Saad, Jalil, Denan and Tahir (2015) that all races portray similar views in the factors leading to drug abuse. The findings also support that 'peer influence' is the key factor that led youth to take drugs.

The community and parents should take part to impede the problem of drug abuse among youngsters. Each and everyone in the society have a role to play as there is no one-size-fits-all approach to deal with the problem of drug abuse. The drug abuse problem, like in economics, fundamentally needs to be understood from a demand and supply perspective. To achieve optimum results, demand and supply initiatives need to be equally effective. The challenge is to build on this success and provide people who use drugs with the best care and support (Vicknasingam, 2017).

For future research, it is suggested that a comprehensive study on youngsters throughout the nation to gauge consciousness on the danger of drug abuse is done. Other determinants such as religiosity and internal strength of individuals could also be considered to further analyse the factors that drag youngsters into drug abuse. According to the Intervention Services, Inc. (2017) the four factors necessary for substance abusers to recover are internal feeling, external motivator, external hope and internal strength. Miller, Davies and Greenwald(2000) in their study among adolescents in the National Comorbidity Survey concluded that low levels of religiosity may be associated with adolescent onset of substance use and abuse. This is supported with a study by Gomes, de Andrade, Izbicki, Almeida and Oliveira (2013) which found that religiosity was found to be a strongly protective factor against drug use among Brazilian university students though more studies are needed to identify the mechanisms by which religiosity exerts this protective influence.

Adolescents are most susceptible to illicit drugs. Preventing the use of illegal drugs, alcohol and tobacco is essential. Drug prevention programs are most effective among the young. Successful substance-abuse prevention leads to reductions in fatalities, violence, unwanted pregnancy, child abuse, sexually transmitted diseases, HIV/AIDS, injuries, cancer, heart disease, and lost productivity. Therefore, prevention of drug abuse among adolescents should be a national public health goal of a nation (Office of National Drug Control Policy, Preventing Drug Abuse, 1999).

\section{ACKNOWLEGMENT}

We are grateful for the financial grants from LESTARI (600-IRMI/MyRA5/3/LESTARI (0051/2016). Special thanks also for assistance provided by Faculty of Business Management, Universiti Teknologi MARA, Malaysia, in carrying out the survey.

\section{REFERENCES}

Abdul Rahman, H. (2015). Alarming rise in drug abuse among youths an alarming trend, Retrieved fromnewsdesk@thesundaily.com. 
INTERNATIONAL JOURNAL OF ACADEMIC RESEARCH IN BUSINESS AND SOCIAL SCIENCES

Vol. 8, No. 11, Nov, 2018, E-ISSN: 2222-6990 @ 2018 HRMARS

Alm, S. (2017). Drug Abuse and Life-Chances-Do Childhood Conditions Matter? Results from a Swedish Life Course Study. Advances in Life Course Research, 32, 1-11. doi:10.1016/j.alcr.2016.11.002

Banks, G., Hadenfeldt, K., Janoch, M., Manning, C., Ramos, K. \& Patterson Silver Wolf, D.A. (2017). Gun Violence and Substance Abuse. Aggression and Violent Behavior, 34, 113-116. doi:10.1016/j.avb.2017.02.002

Bor, J., Cohen, G. H. \& Galea, S. (2017). Population Health in an Era of Rising Income Inequality: USA, 1980-2015. The Lancet, 389(10077), 1475-1490. doi:10.1016/s0140-6736(17)30571-8

Cox, R. (2014). Differential Effects of Parents and Peers on Externalizing Behavior and Drug Use. Acta de Investigación Psicológica, 4, 1491-1509. doi:10.1016/s2007-4719(14)70389-8 doi:10.1016/j.drugalcdep.2016.11.040

Gomes, F.C., de Andrade, A. G., Izbicki, R., Almeida, A. M. \& de Oliveira, L.G. (2013). Religion as a Protective Factor against Drug Use among Brazilian University Students: Elsevier, 45, 29 37. https://doi.org/10.1016/j.rbp.2012.05.010 Retrieved from http:// www.sciencedirect.com/science/article/pii//S1516444613000238

Intervention Services Inc. (2017). An Internal Strength to Remain Sober. Retrieved from https://www.interventionservicesinc.com/intervention-101/addiction-and-recovery/whythey-recover/an-internal-strength/

Long, C., DeBeck, K., Feng, C., Montaner, J., Wood, E. \& Kerr, T. (2014). Income Level and Drug Related Harm among People Who Use Injection Drugs in a Canadian Setting. International Journal of Drug Policy, 25, 458-464. doi:10.1016/j.drugpo.2013.11.011

Miller, L., Davies, M. \& Greenwald, S. (2000). Religiosity and substance abuse among adolescents in the National Comorbidity Survey. Journal of American Academy of Child and Adolescent Psychiatry, 39,1190 - 1197.

Mohd Saad, B., Jalil, S.A., Denan, Z. \& Tahir, N.F. (2015). Drug and Substance Abuse among Youth: A rehabilitation centre in Kuala Lumpur. Retrieved from https://doi.org/10.21834/ebpj.v1i2.281

NIDA. (2016). Understanding Drug Use and Addiction. Retrieved from https://www.drugabuse.gov/publications/drugfacts/understanding-drug-use-addiction

Office of National Drug Control Policy, Preventing Drug Abuse. (1999). Retrieved from http://www.ncjrs.gov/ondcppubs/publications/policy/99ndcs/iv-b.html

Oleinik, A. (2016). Corruption on the Road: A Case Study of Russian Traffic Police. IATSS Research, 40, 19-25. doi:10.1016/j.iatssr.2015.12.001

Schofield, T.J., Conger, R.D. \& Robins, R.W. (2015). Early Adolescent Substance Use in Mexican Origin Families: Peer Selection, Peer Influence, and Parental Monitoring. Drug and Alcohol Dependence, 157, 129-135. doi:10.1016/j.drugalcdep.2015.10.020

Strathdee, S. A., Beletsky, L. \& Kerr, T. (2015). HIV, Drugs and the Legal Environment. International Journal of Drug Policy, 26(Suppl 1), 27-32. doi:10.1016/j.drugpo.2014.09.001

Sundquist, J., Sjostedt, C., Winkleby, M., Li, X., Kendler, K.S. \& Sundquist, K. (2016). Neighborhood Linking Social Capital as a Predictor of Drug Abuse: A Swedish National Cohort Study. Addictive Behaviors, 63, 37-44. doi:10.1016/j.addbeh.2016.07.002 
INTERNATIONAL JOURNAL OF ACADEMIC RESEARCH IN BUSINESS AND SOCIAL SCIENCES

Vol. 8, No. 11, Nov, 2018, E-ISSN: 2222-6990 (C) 2018 HRMARS

Vassiliki, S.P. (2013). Relationships between Parents' Marital Status and the Psychological Well-being of Adolescents in Greece. Retrieved August 20, 2017, from http://www.omicsonline.org/relationships-between-parents-marital-status-and-thepsychological-wellbeing-of-adolescent-in-greece

Vicknasingam, B. (2017). Understanding drug abuse. Retrieved May 30, 2017, from http://www.thestar.com.my/opinion/letters/2017/01/17/understanding-drug-abuse/

Walton, M. A., Epstein-Ngo, Q., Carter, P.M., Zimmerman, M.A., Blow, F.C., Buu, A. \& Cunningham, R. M. (2017). Marijuana Use Trajectories among Drug-Using Youth Presenting to an Urban Emergency Department: Violence and Social Influences. Drug and Alcohol Dependence, 173, 117-125. 